\title{
Voltaire et le Grand Siècle, sous la direction de Jean Dagen et Anne-Sophie Barrovecchio
}

\section{Alessia Del Bianco}

\section{(2) OpenEdition}

1 Journals

\section{Edizione digitale}

URL: http://journals.openedition.org/studifrancesi/8923

DOI: 10.4000/studifrancesi.8923

ISSN: 2421-5856

\section{Editore}

Rosenberg \& Sellier

\section{Edizione cartacea}

Data di pubblicazione: 1 octobre 2008

Paginazione: 458-459

ISSN: 0039-2944

\section{Notizia bibliografica digitale}

Alessia Del Bianco, «Voltaire et le Grand Siècle, sous la direction de Jean Dagen et Anne-Sophie

Barrovecchio», Studi Francesi [Online], 155 (LII | II) | 2008, online dal 30 novembre 2015, consultato il 13 janvier 2021. URL: http://journals.openedition.org/studifrancesi/8923 ; DOI: https://doi.org/10.4000/ studifrancesi.8923

Questo documento è stato generato automaticamente il 13 janvier 2021.

\section{(c) (†) $\odot$}

Studi Francesi è distribuita con Licenza Creative Commons Attribuzione - Non commerciale - Non opere derivate 4.0 Internazionale. 


\title{
Voltaire et le Grand Siècle, sous la direction de Jean Dagen et Anne- Sophie Barrovecchio
}

\author{
Alessia Del Bianco
}

\section{NOTIZIA}

Voltaire et le Grand Siècle, sous la direction de Jean DAGEN et Anne-Sophie BARROVECCHIO, Oxford, Voltaire Foundation, 2006 (SVEC, 2006:10), pp. 441.

1 Duecentocinquant'anni dopo la prima pubblicazione del Siècle de Louis XIV l'Università di Paris-Sorbonne ha organizzato, nel novembre 2001, un Convegno Internazionale dal titolo Voltaire et le Grand Siècle. A cinque anni di distanza, esce a cura di Jean Dagen e Anne-Sophie Barrovecchio l'omonimo volume degli atti, che raccoglie la nutrita serie di interventi presentati in quell'occasione. In un mosaico di punti di vista e di approcci diversi, gli autori ripercorrono la genesi, le fonti, la fortuna di un'opera che ha segnato il punto di inizio di una storiografia critica metodologicamente consapevole. Nella prima sezione, dal titolo «Écrire l'histoire», i relatori si sono interrogati proprio sulla costruzione di un metodo, a monte del Siècle e in corso d'opera, e hanno sottolineato la complessità fortemente chiaroscurale della pittura voltairiana, la quale, pur ispirandosi per molti aspetti alla coeva letteratura encomiastica (Perrault) e pur esibendo a più riprese l'intento di ergersi a monumento della gloria del secolo passato, non rinuncia a indicare sullo sfondo le zone in ombra, in una tensione critica continuamente rinnovata.

2 Alla seconda sezione («Quelle histoire?»), sono affidate una serie di riflessioni sulle caratteristiche di questo nuovo modo di fare storia. Se nella celebre lettera a Dubos o nelle sue Remarques sur l'histoire Voltaire rivendica a chiare lettere la necessità di discernere il vero dal falso, e l'esigenza tutta razionalistica di selezionare accuratamente i dati attendibili, Gianni готті (Le "Siècle de Louis XIV": de l'histoire et de la 
fiction, pp. 81-96) fa notare come l'autore del Siècle adoperi a piene mani strategie retoriche tendenziose, non lontane da quelle impiegate nei contes o nelle facezie. Una scrittura tesa e ironica, quella del Siècle, che accogliendo una figuralità esuberante riesce bene a mettere a nudo i difetti della politica assolutistica e le piccolezze della vita di corte. Jean-François DUNYACH (L'histoire voltairienne entre progrès et décadence: $d u$ Grand Siècle à l'idée de civilisation, pp. 133-146) mostra, dal canto suo, come lo stesso metodo euristico voltairiano, critico e sperimentale, indichi al tempo stesso la magnificenza e la caducità della grandeur di Luigi XIV. Ma quali modelli Voltaire salva nel panorama secentesco? Il Catalogue des écrivains offre un repertorio esaustivo di letterati, artisti, giornalisti che hanno contribuito alla formazione del gusto nel secolo in cui la cultura francese finalmente esce dalla barbarie. Fra i nomi qui esaminati, Descartes, Bossuet, La Fontaine - osteggiato e rifiutato per invidia, sembra indicarci Nicholas CRONK (Voltaire, La Fontaine et les ambivalences du 'siècle de Louis XIV', pp. 255-261) - e l'immancabile Boileau, eletto alla carica di indiscusso maestro di stile. Olivier FERRET (Voltaire et Boileau, pp. 205-222), in particolare, ripercorre le tappe dell'edificazione di un'immagine fittizia del Despréaux, disegnata nel corso dell'intera opera voltairiana.

3 La quarta sezione, infine, mette in campo gli «Enjeux» politico-religiosi del Siècle: i temi della tolleranza, del rapporto con la Chiesa gallicana, e soprattutto la rappresentazione riduttiva e grottesca del giansenismo come movimento politicamente ininfluente, il quale «ne pouvait exciter que des querelles théologiques et des guerres de plume» offrono il destro, come rileva Monique COTTRET (Voltaire au risque du jansénisme: "Le Siècle de Louis XIV" à l'épreuve du jansénisme, pp. 387-397), a una nuova interpretazione del metodo storiografico voltairiano. L'irrinunciabile spirito critico e sperimentale conduce Voltaire a rifiutare ogni finalismo provvidenzialistico, ogni piano trascendente che si sovrapponga al racconto storico per organizzarlo e indirizzarlo verso fini precisi: a differenza di quella d'impronta religiosa, come di quella laica encomiastica, la sua storia si propone come «esquisse», impressione, discorso incompiuto su dati riscontrabili empiricamente.

«Les contributions de notre colloque se laissent assez bien ordonner et ajuster comme les pièces d'un puzzle», osserva Jean DAGEN nella Préface (pp. IX-XXII) al volume, a sottolineare come i diversi interventi, prodotti da studiosi di diversa estrazione e metodo, si lascino ordinare in un quadro interpretativo tutto sommato omogeneo. La narrazione storica voltairiana manifesta l'esigenza impellente, e per l'epoca del tutto nuova, di interpretare il passato per capire e indirizzare le azioni del presente, senza presupporre di necessità una fede ottimistica nel progresso e nella perfettibilità delle società umane. Dagen sottolinea, anzi, come l'impianto ideologico del Siècle si regga su una tensione continua fra la necessità utopica di una progettualità nel futuro e la tragica consapevolezza dell'aleatorietà del corso storico, che non permette il lusso di una proiezione. A chiusura della «Préface», tuttavia, egli rivendica con forza il valore profondo del pensiero filosofico applicato alla storia: «il [Siècle] semble écrit pour rappeler à ceux qui se reposent sur une conception commode de l'histoire, que la pensée véritablement philosophique ne peut et ne doit cesser de se connaître tragique» (p. XXII). 